Check for updates

Cite this: RSC Adv., 2019, 9, 7065

Received 8th December 2018

Accepted 25th February 2019

DOI: $10.1039 / c 8 r a 10083 g$

rsc.li/rsc-advances

\section{Corrosion inhibition of carboxylate inhibitors with different alkylene chain lengths on carbon steel in an alkaline solution}

\begin{abstract}
Bing Lin and Yu Zuo (D)*
The inhibition effects of five organic carboxylate compounds with different alkylene chain lengths on Q235 steel in a simulated carbonation concrete pore solution $(\mathrm{pH}$ 11.5) were studied using quantum chemical calculations, electrochemical measurement and surface analysis. The results show that the adsorption capacity of the inhibitors increases with increasing distance between the $\mathrm{C}=\mathrm{C}$ bond and $\mathrm{COO}-$ group. As the alkylene chain length increases, the absolute surface charge value increases and the inhibition effectiveness tends to increase. C11 shows the best inhibition. The carboxylate inhibitors adsorb on a steel surface by forming $\mathrm{Fe}-\mathrm{OOC}-\mathrm{C}_{x}$ compounds and the $\mathrm{C}=\mathrm{C}$ bonds could enhance the adsorption process.
\end{abstract}

\section{Introduction}

Corrosion leads to the degradation of materials due to the chemical or electrochemical interaction between the materials and the surrounding environments. ${ }^{1}$ The corrosion of reinforcing steel in concretes is the major cause of degradation of concrete structures. Normally, reinforcing steels are protected by the passivation film formed on the surface due to the alkaline environment in concretes. ${ }^{2}$ However, the passive film may be broken by the carbonation of concretes ${ }^{3,4}$ and the presence of chlorides. ${ }^{5,6}$ Pitting corrosion, initiated by the partial breakdown of the passive film, ${ }^{7,8}$ can accelerate the mechanical failure of structural components by perforation or forming crack nucleation sites. ${ }^{7-9}$ The economic aspect combined with security and environmental concerns have provided continuous motivation for the research community to develop new methods to reduce the impact of corrosion. ${ }^{1}$

Corrosion inhibitors are very attractive due to their high efficiency and low costs. ${ }^{2}$ Unfortunately, there are drawbacks for traditional inhibitors such as toxicity and risky effects when the inhibitors are added in poor dosage. The researches on green corrosion inhibitors have been addressed towards cheap and effective molecules with negligible or no environmental impact..$^{1-3,9-11}$ In recent decades, the research on new type organic corrosion inhibitors and the inhibition mechanism has been paid much attention. Marco et al..$^{10}$ studied 80 kinds of organic inhibitors for preventing chloride-induced corrosion, the results show that carboxylate substances, especially poly-carboxylates, showed very good inhibition effectiveness. Carboxylates adsorbed on steel surface through the delocalized electrical charge on

Beijing Key Laboratory of Electrochemical Process and Technology for Materials, College of Materials Science and Engineering, Beijing University of Chemical Technology, Beijing 100029, China. E-mail: zuoy@mail.buct.edu.cn the two oxygen atoms of the carboxylic group, and the alkyl carbon chain could form a hydrophobic layer covered on the passive film. ${ }^{10,11}$ The adsorption of carboxylate inhibitors depends on the physico-chemical properties of the functional groups and electron density at the donor atom. ${ }^{13-16}$ The study by Hefter et al. ${ }^{11}$ revealed that the inhibition performance of monocarboxylates inhibitors in neutral solution are critically dependent upon their chain length. Marco ${ }^{10}$ studied the influence of carbon-chain length for poly-carboxylates of the series ${ }^{-}$OOC$\left(\mathrm{CH}_{2}\right)_{n}-\mathrm{COO}^{-}$( $n$ in the range of $0-7$ ) and pointed out the existence of an optimal chain length for the inhibition effect. The pitting potential $\left(E_{\text {pit }}\right)$ increases first then decreases with the increase of the intermediate chain length, and the $E_{\text {pit }}$ reaches the maximum for an intermediate chain length $(n=3)$. Several researchers ${ }^{12,15,17}$ have studied the effect of carbon chain length of inhibitors in acid solution. They got the same results that the inhibition efficiency increased with the augment of the alkyl chain length attached to imidazolium ring for the inhibitors, which was attributed to the electron-donating effect of alkyl groups. For the past a few years, there was a lot of interests in studying new compounds to inhibit corrosion, as well as in understanding the inhibition mechanism. ${ }^{10}$ Thus, it is important to further understand the effect of carbon chain length on the corrosion inhibition in various environments, particularly in alkaline environments on which there were few previous reports.

This work aims to assess the corrosion inhibition effect as well as the inhibition mechanism of five kinds of organic olefine acid with different carbon chain lengths on Q235 carbon steel in a simulated concrete pore solution. Quantum chemical calculations have been used to predict the anticorrosive capability of the examined inhibitors. The roles and the effects of alkylenel chain length in these inhibitors on corrosion inhibition have been investigated by using different electrochemical measurements and surface techniques. 


\section{Experiment methods}

\subsection{Materials and solutions}

Q235 carbon steel was studied with following chemical composition (wt\%): C 0.11, Si 0.13, Mn 0.74, S 0.028, P 0.012, O 0.01 and Fe balance. The size of the electrochemical test sample was $8 \mathrm{~mm}$ $\times 8 \mathrm{~mm} \times 10 \mathrm{~mm}$. The working electrode was covered with epoxy resin, leaving a $0.64 \mathrm{~cm}^{2}$ area exposed to the test solution. The working surface for all samples was polished by grit papers from $240 \#$ to $1000 \#$, and cleaned with de-ionized water and ethanol.

The testing solution was $0.0021 \mathrm{~mol} \mathrm{~L}^{-1} \mathrm{NaOH}, 0.0042 \mathrm{~mol} \mathrm{~L}^{-1}$ $\mathrm{KOH}$ and $0.02 \mathrm{~mol} \mathrm{~L}^{-1} \mathrm{NaCl}$, which was intended to present the pore solution within a carbonated concrete environment. ${ }^{18}$ The examined inhibitors are listed in Table 1. All the inhibitors used in the experiment were analytical grade chemicals. The $\mathrm{pH}$ value of the testing solution was adjusted to $11.5 \pm 0.2$ by using $0.01 \mathrm{M} \mathrm{NaOH}$ and $0.01 \mathrm{M} \mathrm{HCl}$, and all tests were carried out at room temperature.

\subsection{Quantum chemical calculation}

Quantum chemical calculation was performed using Materials Studio 7.0 software. ${ }^{19-21}$ The Density Functional Theory (DFT) method, B3LYP, combined with the $6-311 \mathrm{G}(\mathrm{d}, \mathrm{p})$ basis ${ }^{22-24}$ set was used in this study. Full geometry optimizations were carried out on carboxylate ions due to the alkaline environment. Quantum chemical parameters were computed including the energy of the highest occupied molecular orbital $\left(E_{\text {Hомо }}\right)$, the energy of the lowest unoccupied molecular orbital $\left(E_{\mathrm{LUMO}}\right)$, energy band gap $(\Delta E)$, chemical potential $(\mu)$, electronegativity $(X)$, chemical hardness $(\eta)$, electrophilicity $(\omega)$ and nucleophilicity $(\varepsilon) \cdot{ }^{19-26}$ The quantum chemical reactivity indices were derived from the frontier molecular orbital energies ( $E_{\mathrm{HOMO}}$ and $\left.E_{\mathrm{LUMO}}\right)$ using appropriate relations (eqn (1)-(5)) as previously reported in literature. ${ }^{18-24}$

$$
\begin{gathered}
\Delta E=E_{\mathrm{LUMO}}-E_{\mathrm{HOMO}} \\
X=-\mu=-\left(E_{\mathrm{LUMO}}+E_{\mathrm{HOMO}}\right) / 2 \\
\eta=-\Delta E / 2 \\
\omega=X^{2} / 2 \eta \\
\varepsilon=1 / \omega
\end{gathered}
$$

\subsection{Electrochemical measurements}

Linear polarization was used to measure the polarization resistance $\left(R_{\mathrm{p}}\right)$ by potential scanning at the rate of $0.1667 \mathrm{mV}$

Table 1 The examined inhibitors

\begin{tabular}{lll}
\hline Lable & Inhibitor & Molecular structure \\
\hline $\mathrm{C} 3$ & Acrylic acid & $\mathrm{CH}_{2}=\mathrm{CH}-\mathrm{COO}^{-}$ \\
C5 & Allylacetic acid & $\mathrm{CH}_{2}=\mathrm{CH}-\left(\mathrm{CH}_{2}\right)_{2}-\mathrm{COO}^{-}$ \\
C7 & 6-Heptenoic acid & $\mathrm{CH}_{2}=\mathrm{CH}-\left(\mathrm{CH}_{2}\right)_{4}-\mathrm{COO}^{-}$ \\
C11 & Undecylenic acid & $\mathrm{CH}_{2}=\mathrm{CH}-\left(\mathrm{CH}_{2}\right)_{8}-\mathrm{COO}^{-}$ \\
C18 & Oleic acid & $\mathrm{CH}_{3}-\left(\mathrm{CH}_{2}\right)_{7}-\mathrm{CH}=\mathrm{CH}-\left(\mathrm{CH}_{2}\right)_{7}-\mathrm{COO}^{-}$
\end{tabular}

$\mathrm{s}^{-1}$ in the range $E_{\text {corr }} \pm 10 \mathrm{mV}$, and the results was fitted by CVIEW2 software. The cyclic potentiodynamic polarization (CPP) curves and impedance measurements were tested in the test solution with a CS350 electrochemical workstation (Correst, Wuhan, China). The CPP tests were measured after $1 \mathrm{~h}$ immersion with a $0.1667 \mathrm{mV} \mathrm{s}^{-1}$ scan rate from $-300 \mathrm{mV}$ below the open circuit potential in the anodic direction until the current density increased up to $0.02 \mathrm{~mA} \mathrm{~cm} \mathrm{~cm}^{-2}$, then the potential scanning was reversed at the same scanning rate until the test ended. Impedance measurements, in order to calculate the potential of zero charge (PZC) of steel, ${ }^{27,28}$ were carried out using AC signals of a $15 \mathrm{mV}$ potential perturbation and the scanning frequency range was $100 \mathrm{kHz}$ to $0.01 \mathrm{~Hz}$. The impedance data were fitted by ZSimpWin software. A three-electrode system was used in the electrochemical tests. A platinum electrode functioned as counter electrode, the steel specimen worked as the working electrode and the reference electrode was a saturated calomel reference electrode (SCE). Six tests were run under each experimental condition, and the electrochemical data form the parallel tests were statistically analyzed.

\subsection{Concrete environment}

To further confirm the inhibition effect of tested inhibitors for steel in concrete environment, the corrosion rate of Q235 steel in concrete was measured. Reinforced concrete specimens were prepared with 425\# Portland cement, dried fine river sand and distilled water with the ratio of $1: 3: 0.7$ (wt $\%) .{ }^{28,29}$ The studied inhibitors were added into the distilled water $(0.1 \%$ of the total weight of concrete) and the $\mathrm{pH}$ value of the water was adjusted to 7. The steel sample was positioned in order to have a concrete cover of $20 \mathrm{~mm}$ thick. The concrete specimens were dried at room temperature for three days and then immersed in 3.5\% (wt\%) NaCl solution ( $\mathrm{pH} 7$ ). The corrosion rate of Q235 carbon steel was measured by linear polarization test with a threeelectrode system as mentioned above, up to 20 days.

\subsection{Weight loss measurements}

Samples with size of $50 \mathrm{~mm} \times 25 \mathrm{~mm} \times 2 \mathrm{~mm}$ were immersed in $500 \mathrm{~mL}$ test solution without or with various concentrations of inhibitors at room temperature $\left(25 \pm 1{ }^{\circ} \mathrm{C}\right)$ for 7 days. Three parallel samples were used for each condition. After immersion, the corrosion products were removed by $17 \% \mathrm{HCl}$ solution with $3.5 \mathrm{~g} \mathrm{~L}^{-1}$ hexamethylene tetramine (HMTA) for $10 \mathrm{~min}$, and the samples were cleaned with de-ionized water and ethanol, then were weighted. The corrosion rate (CR) and inhibition efficiency (IE\%) were calculated according the weight loss results.

\subsection{Surface observation and characterization}

A $4 \mathrm{~mm} \times 4 \mathrm{~mm} \times 3 \mathrm{~mm}$ carbon steel sample was polished to 1000\# grit, rinsed with de-ionized water and ethanol. After immersion in test solution without and with 500 ppm inhibitors for $24 \mathrm{~h}$. The steel coupons were rinsed with de-ionized water, then dried in hot air.

Scanning electron microscopy (SEM) was used to observe the surface morphology of the samples with a Quanta 650 instrument (FEI, USA). Electrochemical scanning tunneling 
microscope (EC-STM) was used to detect the 3D morphology and surface roughness of the steel samples, and the tunneling current was $50 \mathrm{nA}$ and the scanning range was $2000 \mathrm{~nm}$. Six parallel scans were performed on each sample.

Raman spectrum was obtained using a Raman Renishaw microscopy (system 3000) coupled to an Olympus optical microscope and a CCD $(600 \times 400$ pixels $)$ detector. X-ray photoelectron spectroscopy (XPS) test was performed to analyze the surface composition on a Thermo Fisher ESCALAB 250 spectrometer. The binding energy values of the peaks were calibrated by C $1 \mathrm{~s}$ peak at $248.8 \mathrm{eV}$.

\section{Results and discussion}

\subsection{Quantum chemical calculation}

Quantum chemical calculation was used to investigate the interaction between the inhibitors and the steel surface. Adsorption is well known to be the key mechanism of organic inhibitor action, which suggests that the inhibitor molecules are adhered on the metal surface area where the cathodic and anodic reactions take place. ${ }^{25}$ The optimized molecular structures, highest occupied molecular orbital (HOMO) and lowest unoccupied molecular orbital (LUMO) electronic density distributions are shown Fig. 1. Obviously, HOMO is distributed around the oxygen atom of the carboxylate radical while LUMO is located near the $\mathrm{C}=\mathrm{C}$ double bond of the inhibitors. Hence the studied compounds can donate electrons via carboxylic group but majorly host accepted electrons through the $\mathrm{C}=\mathrm{C}$ bonds.

As we know, quantum chemical calculation is a very important tool to establish a useful correlation between molecular structure and corrosion inhibition efficiency. ${ }^{16,24}$ In consistent with Fukui theory, ${ }^{26} \mathrm{HOMO}$ and LUMO of reacting species could affect the transition of electrons during the adsorption process. $E_{\text {Hомо }}$ is normally used to describe the electron-donating ability of a compound. Generally, molecules which have higher $E_{\text {Hомо }}$ are more easily to donate electrons to the unfilled molecular orbital of suitable acceptor molecules with low energy. ${ }^{21}$ Previous studies showed that the inhibition efficiency increases with the increasing $E_{\text {HOMO }}$ values. ${ }^{23,26}$ In contrast, the

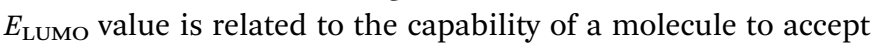
electrons. Molecules with a lower $E_{\mathrm{LUMO}}$ are more easily to accept electron and accommodate the redundant charge of the metal surface. ${ }^{21}$ In addition, it was shown that the inhibitor not only donates electron to the unoccupied d orbital of the metal surface but also accepts electron from the d orbital of the metal leading to the formation of a feedback bond. ${ }^{23,26}$ The calculated quantum chemical parameters are listed in Table 2. As the carbon chain length increases the $E_{\text {HOMO }}$ slightly increase, and the $E_{\mathrm{LuMO}}$ decreases as the carbon chain length increases except for the sodium oleate (C18), which may be due to that the distance between the $\mathrm{C}=\mathrm{C}$ bond and $-\mathrm{COO}^{-}$is smaller than that in 10-undecylenic acid (C11). The $E_{\mathrm{LuMO}}$ decreases as the distance between the $\mathrm{C}=\mathrm{C}$ bond and $-\mathrm{COO}^{-}$increases. $\Delta E$ is an important parameter as a function of reactivity of the inhibitor molecule towards the adsorption on the metallic surface. As the energy gap $(\Delta E)$ decreases the adsorption energy between the inhibitors and iron surface would increase. ${ }^{22,30}$ Bereket et al. ${ }^{31}$ showed that the excellent corrosion inhibitors are usually organic compounds which not only offer electrons to unoccupied orbital of the metal but also accept free electrons from the metal. The results indicate that the energy gap decreases as the

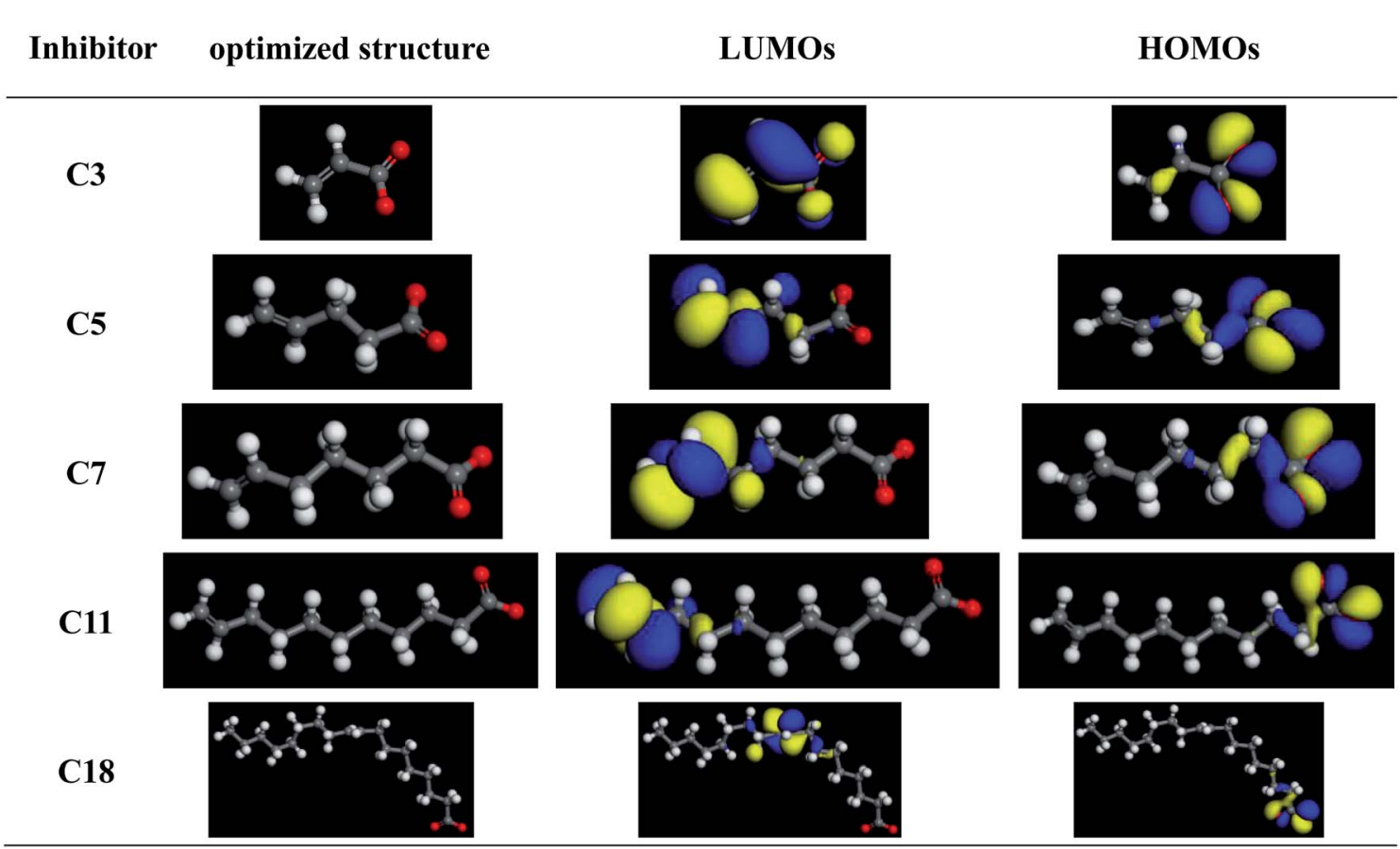

Fig. 1 The optimized structures and HOMO and LUMO of studied compounds. 
Table 2 Calculated quantum chemical parameters for the inhibitors

\begin{tabular}{|c|c|c|c|c|c|c|c|}
\hline & $E_{\text {номо }}$ & $E_{\text {LUMO }}$ & $\Delta E$ & $\mu$ & $X$ & $\eta$ & $\Delta U$ \\
\hline C3 & -0.575 & 4.555 & 5.13 & 1.99 & -1.99 & 2.565 & 1.752 \\
\hline C5 & -0.696 & 3.947 & 4.643 & 1.626 & -1.626 & 2.325 & 1.858 \\
\hline C7 & -0.581 & 3.035 & 3.161 & 1.227 & -1.227 & 1.808 & 2.275 \\
\hline C11 & -0.519 & 2.161 & 2.68 & 0.821 & -0.821 & 1.34 & 2.918 \\
\hline C18 & -0.523 & 2.408 & 2.931 & 0.943 & -0.943 & 1.466 & 2.710 \\
\hline
\end{tabular}

distance between the $\mathrm{C}=\mathrm{C}$ bond and $-\mathrm{COO}^{-}$increases. $\mathrm{C} 11$ that shows the lowest $\Delta E$ may have the best inhibition effect.

The obtained results in Table 2 show that the electronegativity increases as the carbon chain length increases, in consistent with the decrease of the chemical potential. As it is known, the absolute hardness and softness are important properties to measure the molecular stability and reactivity. Chemical hardness $(\eta)$ fundamentally signifies the resistance to deformation or polarization of the electron clouds of the atoms, ions or molecules under small perturbation of chemical reaction. ${ }^{26,30}$ Whereas, a hard molecule has a large energy gap and a soft molecule has a small energy gap. Our result shows that the $\eta$ value decreases with the increase of the distance between the $\mathrm{C}=\mathrm{C}$ bond and $-\mathrm{COO}^{-}$.

The fraction of electrons transferred from the inhibitor to metallic surface $(\Delta N)$ is calculated by eqn $(6):^{22-24,26}$

$$
\Delta N=\frac{\mathrm{X}_{\mathrm{Fe}}-\mathrm{X}_{\mathrm{inh}}}{2\left(\eta_{\mathrm{Fe}}+\eta_{\mathrm{inh}}\right)}
$$

where, $X_{\mathrm{Fe}}$ and $X_{\mathrm{inh}}$ represents the electronegativity of Fe metal and inhibitor, respectively. $\eta_{\mathrm{Fe}}$ and $\eta_{\mathrm{inh}}$ are the chemical hardness values of Fe metal and inhibitor, respectively. In order to calculate the $\Delta N$ of each inhibitor, the theoretical values of $X_{\mathrm{Fe}}$ $=7 \mathrm{eV}$ (ref. 22 and 23) and $\eta_{\mathrm{Fe}}=0$ were used assuming that $E_{\text {HOMO }}=E_{\text {LUMO }}$ for a metallic bulk. ${ }^{22}$ The positive value of $\Delta N$ indicates that the molecules act as an electron acceptor, while a negative value of $\Delta N$ indicates that the molecules act as electron donor. If $\Delta N<3.6$, the inhibition efficiency increases with increasing electron donating ability at the metal surface. ${ }^{26,32}$ In this study, the calculated $\Delta N$ is less than $3.6 \mathrm{eV}$, which means that the inhibitor molecules have the tendency to donate electrons to the metal surface, similar to previous studies. ${ }^{23,26}$ In addition, the $\Delta N$ value increases with increasing distance between the $\mathrm{C}=\mathrm{C}$ bond and $-\mathrm{COO}^{-}$.

From the quantum chemical calculation results, the inhibition effect was influenced by the distance between the $\mathrm{C}=\mathrm{C}$ bond and $-\mathrm{COO}^{-}$, and the inhibition effect increases as the distance increases. C11 is the best inhibitor in this study.

\subsection{Electrochemical measurements}

3.2.1 The inhibition effect for different chain length in various concentrations. Electrochemical measurements were performed for the Q235 carbon steel immersed in the simulated carbonated concrete pore solution with different concentrations of study compounds for $1 \mathrm{~h}$.

Fig. 2 shows the open circuit potential (OCP) and the $R_{\mathrm{p}}$ results. The OCP for the uninhibited is about $-355 \mathrm{mV}$, and the

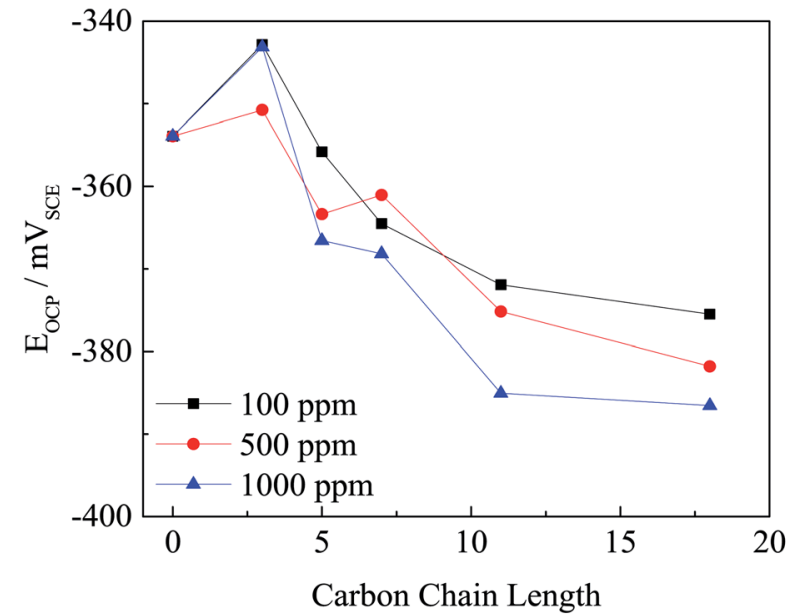

a

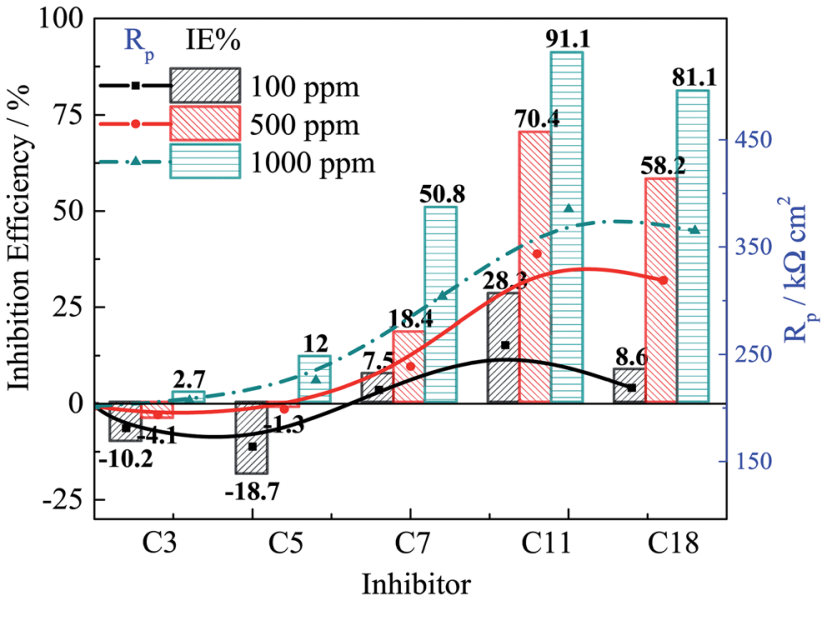

b

Fig. $2 E_{\mathrm{OCP}}(\mathrm{a})$ and $R_{\mathrm{p}}$ (b) values of Q235 carbon steel in test solution with different inhibitors.

OCP slightly increases after adding test inhibitors. As the compounds carbon chain length increases, the OCP values decreases. This result is the same to the literature, ${ }^{\mathbf{1 1}}$ indicating the olefin carboxylate compounds act as mix-type inhibitor in the test system. ${ }^{\mathbf{1 0 , 1 1}}$ In addition, as the inhibitor concentration increases the OCP slightly decreases, which might be attributed to the increased adsorption quantity and the surface coverage.

As the carbon chain length increases, the $R_{\mathrm{p}}$ value shows an increasing tendency, which is due to the stero-hindrance effect of the carbon chain. The adsorbed inhibitor could form a hydrophobic barrier on the steel surface, and repress the corrosion reaction. ${ }^{\mathbf{1 0 - 1 2}}$ The $R_{\mathrm{p}}$ value increases as the inhibitor concentration increases, especially for the inhibitors with more carbon atoms. According to the inhibition efficiency (IE\%) calculated from the $R_{\mathrm{p}}$, in Fig. 2, the short chain length compounds are either slightly corrosive (low concentration for C3 and C5) or as weak inhibitors (high concentration for C3 and C5 and low concentration for other inhibitors) for carbon steel. The inhibition effectiveness increases as the carbon chain 
length increases, especially for the high concentration inhibitors, and the highest IE\% was obtained in solution with $1000 \mathrm{ppm}$ C11. These results confirm the results of the quantum chemical calculation.

In order to further understand the inhibition mechanism, the potential of zero charge (PZC) was measured for Q235 carbon steel in test solution with 500 ppm different inhibitors. The PZC plays a very important role in the electrostatic adsorption process. ${ }^{27,33-35}$ Fig. 3a shows the variation of $C_{\mathrm{dl}}$ with the applied potential and Fig. $3 \mathrm{~b}$ shows the measured PZC and the open circuit potential (OCP) values in test solution with different inhibitors. The surface charge of carbon steel may be obtained at OCP using the equation $\varphi=E_{\mathrm{OCP}}-E_{\mathrm{PZC}} \cdot{ }^{27,33}$ For the un-inhibited situation, at OCP carbon steel surface carries excess positive charge in test solution. This result is similar to the literature, ${ }^{27,33-35}$ which favors the adsorption of the

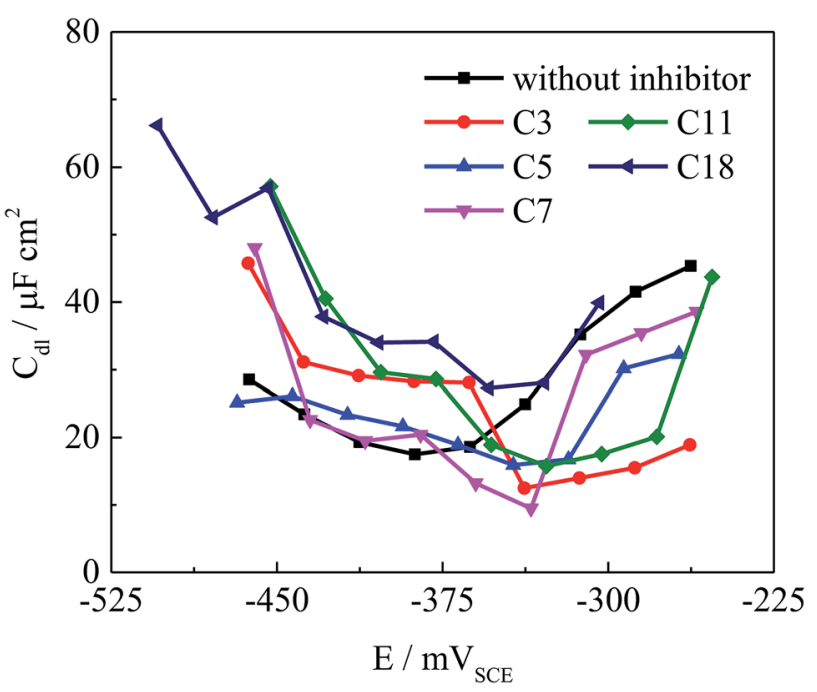

a

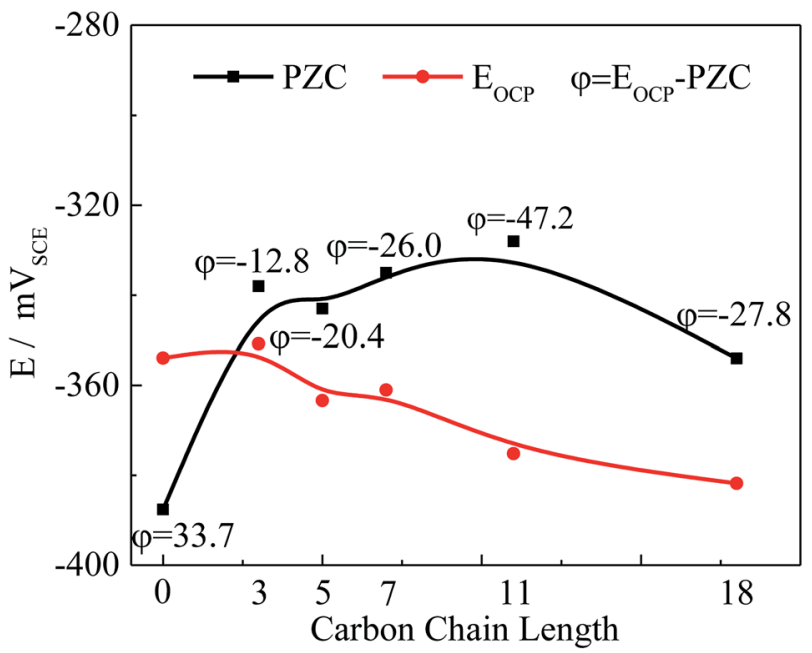

b

Fig. 3 (a) Results of PZC measurement in test solution without and with various inhibitors, (b) the relationship between PZC and OCP. negatively charged $\mathrm{Cl}^{-}$and $\mathrm{OH}^{-}$onto the carbon steel surface. After adding 500 ppm different compounds, the PZC increases and the $\varphi$ value changed to negative, which is attributed to the adsorption of the inhibitors on carbon steel. The absolute $\varphi$ value increases as the carbon chain length of compounds increases, showing the same tendency of the quantum chemical calculation results. The inhibitor could be attracted to the steel surface by static electricity (physical adsorption), ${ }^{36}$ and the adsorption can directly occur through sharing lone electron pair of the oxygen in $-\mathrm{COO}^{-}$with the unoccupied d orbital of iron atoms to form coordinate covalent bond (chemical adsorption). ${ }^{37}$ Moreover, the double bond in the compounds allows back donation of iron d-electrons to form feedback bond in turn since the existence of various orientations of iron's d orbital. ${ }^{35,36}$

3.2.2 The polarization curves for Q235 carbon steel. The polarization curves for Q235 carbon steel immersed in test solution with different inhibitors are shown in Fig. 4. The polarization curves exhibit a common passivation-pitting corrosion behavior. After adding inhibitors, the curves still show the characteristics of passivation-pitting corrosion. As shown in Fig. 5a, the $i_{\text {corr }}$, calculated by Tafel extrapolation, decreases after adding inhibitors, and further declines when the inhibitor concentration increases. The IE\% results obtained by polarization curves are consistent with the results calculated by $R_{\mathrm{p}} . \mathrm{IE} \%$ value increases as the inhibitor concentration increases especially for the long carbon chain length inhibitor. Under the same concentration, the IE\% increases as the carbon chain length increases. The test inhibitors would form adsorption film on the steel surface. ${ }^{\mathbf{1 0 , 1 1}}$ As the alkylene chain length increases, the inhibitor would more easily adsorb on the steel surface, which is consist with the results of quantum chemical calculation. In addition, the adsorption film formed by the longer alkylene carbon chain have better hydrophobic ability. ${ }^{38}$

Pitting potential $\left(E_{\text {pit }}\right)$ is the potential at which the anodic current increases rapidly, ${ }^{\mathbf{1 0}, 39}$ and localized corrosion starts above this potential. As shown in Fig. 5, after adding 100 ppm different inhibitors the $E_{\text {pit }}$ slightly increases, and the alkylene chain length has barely effect on $E_{\text {pit }}$ at this concentration. The $E_{\text {pit }}$ value increases obviously as the inhibitor concentration increases, which might be attributed to the selective adsorption of inhibitor ions in competition with chloride ions at the active sites on the steel surface in early stage of immersion. The selective adsorption will lead to a heterogeneous adsorption which will effectively reduce the susceptibility to pitting corrosion. In addition, carboxylate reaches the metal surface before chloride ions in a competition. ${ }^{38}$ Self-aggregation of carboxylates at steel/electrolyte interface could form a new protective film on passivation film, and the protection ability of the hydrophobic film would be affected by the alkylene chain length. The repassivation potential $\left(E_{\mathrm{rep}}\right)$ is the intersection potential of the forward and reverse scans, and the steel potential must be above $E_{\text {rep }}$ for existing pits to propagate. ${ }^{40}$ The addition of inhibitor leads the increasing of $E_{\text {rep }}$ as the inhibitor concentration increases. The dramatical increase of $E_{\text {rep }}$ for C3 treated steel might be attributed to that the adsorption process is affected by the combination of inductive effect and resonance 


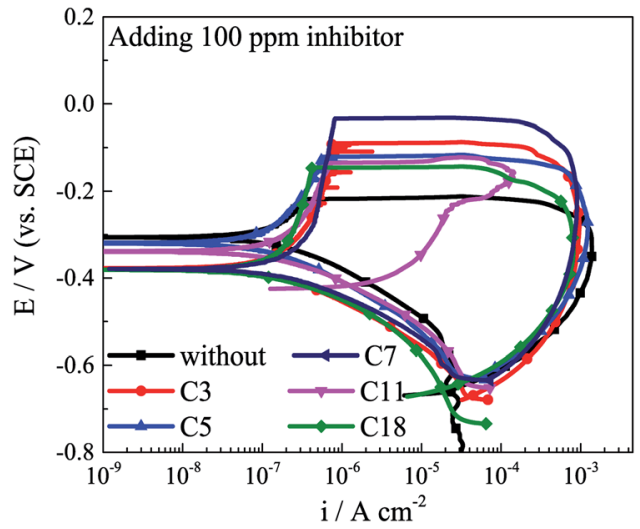

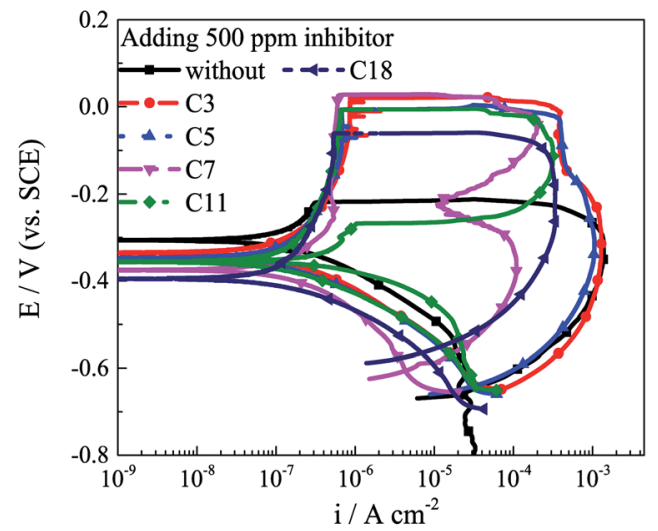

b

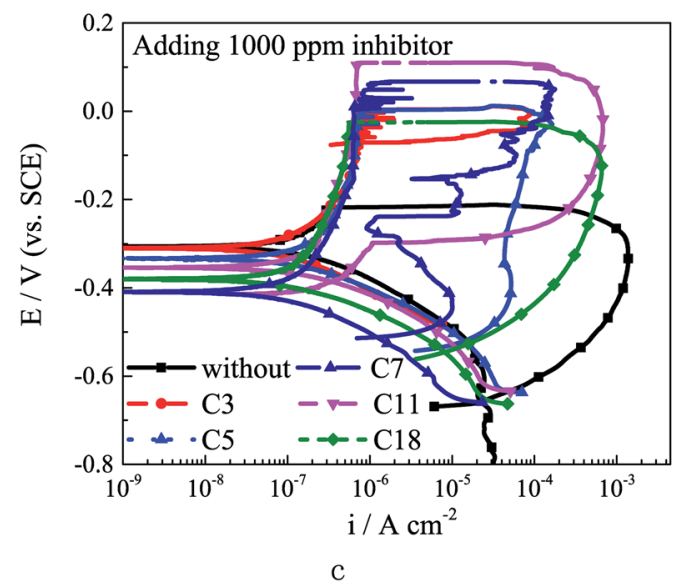

Fig. 4 The CPP curves for Q235 carbon steel in test solution with different inhibitors: (a) 100 ppm inhibitor; (b) 500 ppm inhibitor; (c) 1000 ppm inhibitor.

effect on the electron density of the molecule. ${ }^{10}$ The inductive effect depends on the electronegativity of the substituent group $^{10}$ and the short alkylene chain of $\mathrm{C} 3$ leads the electron cloud migration. The $E_{\text {rep }}$ increases as the alkylene chain length increases. The carboxylate inhibitor could affect the repassivation process by a chelate effect to form complexes with iron ions, ${ }^{38}$ which could precipitate on the bottom of pits to form protective film. The results of polarization curves indicate that the carboxylate inhibitor could enhance the corrosion resistance of both general corrosion and localized corrosion.

3.2.3 The inhibition effect in reinforced concrete. In order to confirm the inhibition effect and the potential application of tested inhibitors in reinforced concrete, the corrosion rate of Q235 steel in concrete environment was measured. Fig. 6 shows the $R_{\mathrm{p}}$ values and the corrosion rate of Q235 carbon steel in concrete with different inhibitors. In the concrete without inhibitor, the $R_{\mathrm{p}}$ of Q235 steel increases and the corrosion rate decreases as the immersion time increases, which might due to the stability of passivation film formed on steel surface increases. In the concrete samples with C7, C11 and C18, the $R_{\mathrm{p}}$ of Q235 steel are obviously higher than that in concrete without inhibitor. As the immersion time increases, the $R_{\mathrm{p}}$ decreases in the first 4 days then increases, while the corrosion rate remain low values during the testing time, which means the inhibitor could effectively increase the polarization resistance of steel and decreases the corrosion rate. On the other hand, for the concrete samples with $\mathrm{C} 3$ and $\mathrm{C} 5$, the $R_{\mathrm{p}}$ is lower and the corrosion rate is higher compared with those of the sample without inhibitor. Although the testing time is relatively short, above results show that the inhibition effect of tested inhibitors in concrete environment are consistent with the results in carbonation SCP solution, and C11 shows the best inhibition effect in concrete environment.

\subsection{Adsorption isotherm}

Table 3 shows the corrosion rate (CR) and inhibition efficiency (IE\%) values obtained from weight loss method at different concentrations of carboxylate compounds after 7 days at room temperature $\left(25^{\circ} \mathrm{C}\right)$. The corrosion rate decreases gradually and the corrosion efficiency increases along with the increase of the alkylene chain length. The IE\% values obtained by weight loss are consist with the results of electrochemical measurements and the maximum IE\% is $90.2 \%$ at $1000 \mathrm{ppm}$ C11. The IE\% increases with the increasing inhibitor concentration, which reveals that the inhibitor ions may compete with chloride ions and the adsorption could take place via electrostatic attraction between the cations and ions from inhibitor and the steel surface. ${ }^{41,42}$ 

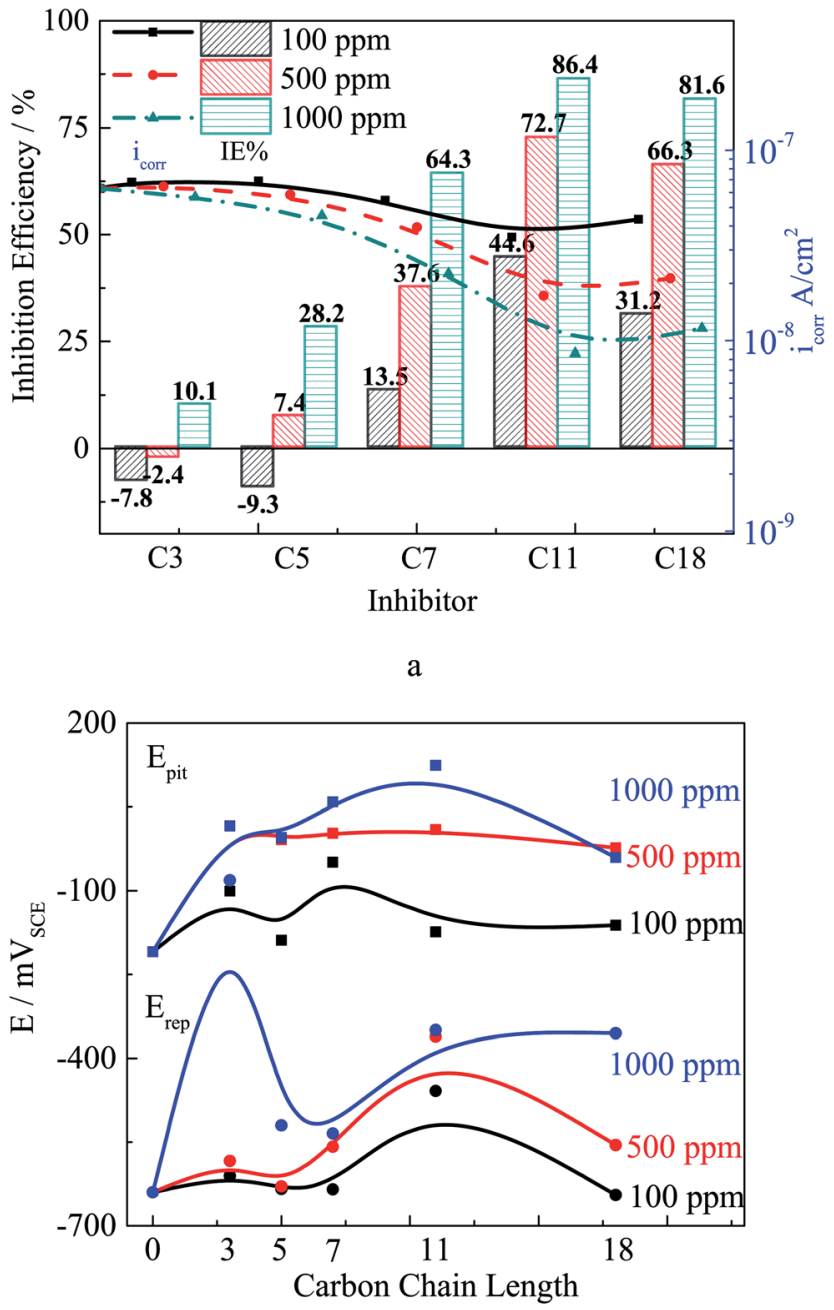

b

Fig. 5 The polarization parameters of Q235 steel in test solution with different inhibitors: (a) corrosion current density and inhibition efficiency; (b) pitting potential and repassivation potential.

The adsorption type of inhibitors on the steel surface, such as physisorption or chemisorption, can provide more information about the properties of the inhibition effect. ${ }^{21,25}$ The surface
Table 3 Corrosion rate (CR/mm y $\mathrm{m}^{-1}$ ) and inhibition efficiency (IE\%) of Q235 steel immersed in test solution for 7 days

\begin{tabular}{lllllll}
\hline Inhibitor & & C3 & C5 & C7 & C11 & C18 \\
\hline Without & CR & 0.1107 & & & & \\
$100 \mathrm{ppm}$ & CR & 0.1189 & 0.1240 & 0.0980 & 0.0726 & 0.0931 \\
& IE\% & $-7.35 \%$ & $-12 \%$ & $11.5 \%$ & $34.4 \%$ & $15.9 \%$ \\
$300 \mathrm{ppm}$ & CR & 0.1126 & 0.1153 & 0.0896 & 0.0434 & 0.0584 \\
& IE\% & $-1.7 \%$ & $-4.1 \%$ & $19.1 \%$ & $60.8 \%$ & $47.3 \%$ \\
$500 \mathrm{ppm}$ & CR & 0.1072 & 0.1075 & 0.0825 & 0.0309 & 0.0425 \\
& IE\% & $3.2 \%$ & $2.9 \%$ & $25.5 \%$ & $72.1 \%$ & $61.6 \%$ \\
$750 \mathrm{ppm}$ & CR & 0.1062 & 0.0981 & 0.0617 & 0.0161 & 0.0251 \\
& IE\% & $4.1 \%$ & $11.4 \%$ & $44.3 \%$ & $85.5 \%$ & $77.3 \%$ \\
$1000 \mathrm{ppm}$ & CR & 0.1053 & 0.0901 & 0.0492 & 0.0109 & 0.0179 \\
& IE\% & $4.9 \%$ & $18.6 \%$ & $55.6 \%$ & $90.2 \%$ & $83.8 \%$
\end{tabular}

coverage $(\theta)$, calculated by the weight loss results, are used to find the best adsorption isotherm..$^{25}$ In the present study, the $\theta$ value is calculated by the weight loss method $(\theta=0.01 \times \mathrm{IE} \%$ (ref. 21 and 25)). The general equations for the Langmuir isotherm models is: $:^{21,25,28}$

$$
\frac{C_{\mathrm{inh}}}{\theta}=\frac{1}{K_{\mathrm{ads}}}+C_{\mathrm{inh}}
$$

where $K_{\text {ads }}$ is the equilibrium constant of the adsorption/ desorption process ${ }^{43}$ and $C_{\mathrm{inh}}$ is the concentration of tested inhibitor. The $K_{\text {ads }}$ value is an indicator about the degree of adsorption. The higher value of $K_{\text {ads }}$, the stronger the adsorption of inhibitor on metal surface. ${ }^{21}$ As shown in Fig. 7, the fitted straight lines are obtained from the plot of $\theta /(1-\theta)$ versus $C_{\mathrm{inh}}$. The strong correlation $\left(R^{2}>0.90\right)$ suggests the adsorption of all the tested inhibitors on carbon steel surface follows this isotherm. Langmuir isotherm assumes that the adsorbed molecules occupy only one site and there are no interactions with other adsorbed species. ${ }^{\mathbf{2 5 , 4 4}}$

The change of Gibbs free energy of adsorption $\left(\Delta G_{\text {ads }}\right)$ is calculated by following equation: ${ }^{21,25,28}$

$$
\Delta G_{\mathrm{ads}}=-R T \times \ln \left(55.5 \times K_{\mathrm{ads}}\right)
$$

where $R$ is the gas constant (8.314) and $T$ is the absolute temperature $(298 \mathrm{~K})$. The value of 55.5 is the concentration of

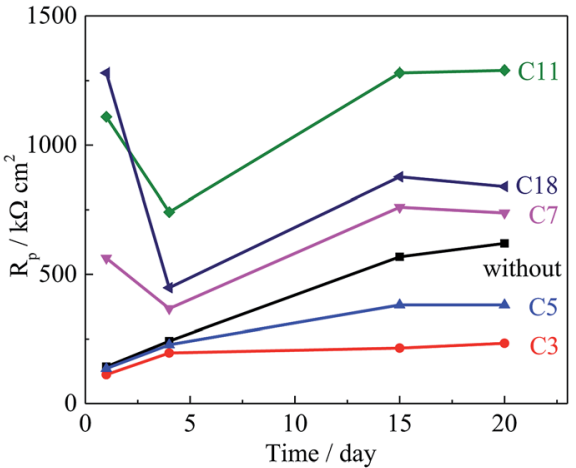

a

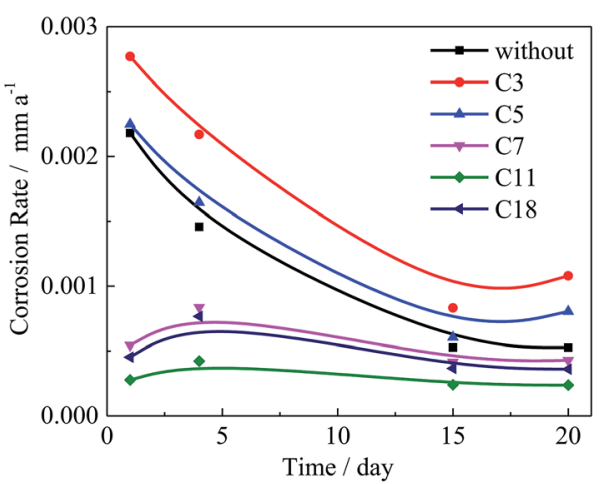

b

Fig. $6 R_{\mathrm{p}}$ values and corrosion rate of Q235 carbon steel in concrete samples with different inhibitors: (a) $R_{\mathrm{p}}$ (b) corrosion rate. 


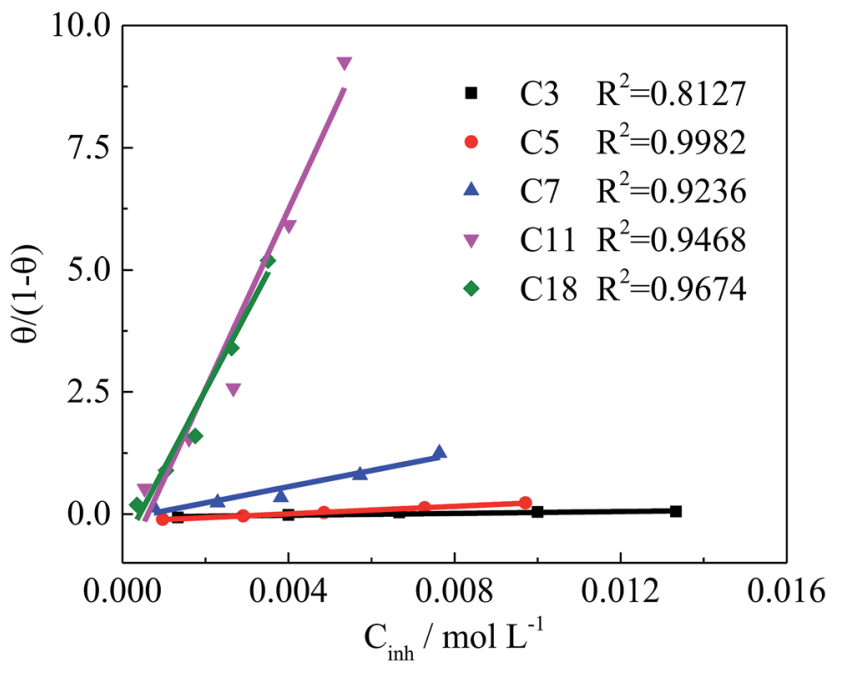

Fig. 7 The relationship between $\theta /(1-\theta)$ and $C_{\text {inhn }}$.

water in solution in $\mathrm{mol} \mathrm{L}^{-1} \cdot{ }^{33}$ The calculated $K_{\text {ads }}$ and $\Delta G_{\text {ads }}$ are shown in Table 4 . The negative values of calculated $\Delta G_{\text {ads }}$ implies spontaneity of the adsorption process and stability of the adsorbed film on the carbon steel surface. ${ }^{25,33}$ The magnitude of the $\Delta G_{\text {ads }}$ determines the nature of the adsorption process. The obtained $\Delta G_{\text {ads }}$ values for $\mathrm{C} 3$ and C5 are less negative than $-20 \mathrm{~kJ} \mathrm{~mol}^{-1}$ (for physisorption), and the obtained $\Delta G_{\text {ads }}$ values for $\mathrm{C} 7, \mathrm{C} 11$ and C18 are more negative than $-20 \mathrm{~kJ} \mathrm{~mol}^{-1}$ and less negative than $-40 \mathrm{~kJ} \mathrm{~mol}^{-1}$ (for chemisorption). This suggests that the C3 and C5 could adsorb on carbon steel surface via physisorption, and the C7, C11 and C18 absorb on steel surface via both physisorption and chemisorption. The chemisorption is via donor-acceptor interactions between d-orbital of iron atoms, including the displacement of adsorbed water molecules from the steel surface and the lone $\mathrm{sp}^{2}$ electron pairs present on the $\mathrm{O}$ atoms, blocking the active sites on the steel surface and leading to decrease of corrosion. ${ }^{41,45}$ Previous authors have reported that for monocarboxylates when the carbon chain length was 7 the inhibitor showed the best inhibition. ${ }^{11}$ On the other hand, for polycarboxylates the pitting potential reached the maximum at an intermediate chain length $(n=3) \cdot{ }^{10}$ In the present study, the optimal carbon chain length for corrosion inhibition is 11 , which may be attributed to the hydrophobic effect and the enhanced adsorption by $\mathrm{C}=\mathrm{C}$ bonds in the carbon chain. The above results indicate that the effect of the carbon chain length on inhibition efficiency is closely related to the environmental parameters, such as $\mathrm{pH}$ and the species in the solution, which

Table 4 Langmuir parameters for the adsorption of test inhibitors on Q235 carbon steel surface

\begin{tabular}{lrcccc}
\hline Inhibitor & C3 & C5 & C7 & C11 & C18 \\
\hline$K_{\text {ads }}$ & 9.63 & 38.6 & 166.1 & 1842.1 & 1603.3 \\
$\Delta G_{\text {ads }}\left(\mathrm{kJ} \mathrm{mol}^{-1}\right)$ & -15.56 & -19.00 & -22.62 & -28.58 & -28.23
\end{tabular}

would obviously affect the adsorption and film forming processes of the inhibitor on the surface.

\subsection{Surface analysis}

3.4.1 Surface morphology. The Q235 carbon steel specimens were immersed in the pH 11.5 solution with $500 \mathrm{ppm}$ different additions of the inhibitors. After 24 hours exposure, the surface morphology of specimens was mapped by SEM and EC-STM. Fig. 8 presents the surface morphology of the samples. The Q235 steel surface of treated by C3 shows a corroded surface with localized breakdown of the passive film. The surface treated by C5 and C7 are similar, and the particles precipitated on the steel surface might be the corrosion products. There are some grinding traces on the surface treated by C11 or C18. This reveals that C3 would promote the locality breakdown of passivation film while $\mathrm{C} 11$ and $\mathrm{C} 18$ have better corrosion inhibition.

The overall 3D topography of the steel specimens under experimental condition was provided by EC-STM. The roughness values provide important information about the inhibition efficiency ${ }^{\mathbf{4 6}}$ and the corresponding height profile graph is shown in Fig. 9. Compared with the sample immersed in the solution without inhibitor, after adding C3 and C5, corrosion of the carbon steel was enhanced. The surface roughness of the steel decreases obviously as the alkylene chain length increases. These 3D topographies and average roughness values reveal that the corrosion inhibitive ability of C11 and C18 are much better than the other inhibitors. The results of surface morphology are consistent with the electrochemical test and weight loss test data.

3.4.2 XPS and Raman spectroscopy characterization. In order to determine the surface composition of the Q235 carbon steel immersed in the test solution with different inhibitors, XPS analysis was used to characterize the steel surface treated by 500 ppm different inhibitors for 24 hours. The obtained high-resolution peaks for $\mathrm{C} 1 \mathrm{~s}, \mathrm{O} 1 \mathrm{~s}$ and $\mathrm{Fe} 2 \mathrm{p} 3 / 2$ core levels are fitted and shown in Fig. 10.

As shown in Fig. 10a, the first peak at 706.7 $\pm 0.2 \mathrm{eV}$ (ref. 47) is attributable to metallic iron on the sample surface. The peak at $707.6 \pm 0.3 \mathrm{eV}$ is assigned to $\mathrm{FeO}$, and the peak at $710.7 \pm$ $0.3 \mathrm{eV}$ is assigned to $\mathrm{Fe}^{3+}$ on the steel surface or a certain degree of oxidation of $\mathrm{Fe}\left(\mathrm{Fe}_{2} \mathrm{O}_{3} / \mathrm{Fe}_{3} \mathrm{O}_{4}\right) \cdot{ }^{22}$ Both the preparation process or corrosion reactions during immersion process could result in iron atoms of different valences. ${ }^{22,48}$ The peak at $713.5 \pm 0.4 \mathrm{eV}$ can be ascribed to the satellite of $\mathrm{Fe}^{3+}$ which is probably related to the presence of $\mathrm{FeCl}_{3}$ from the testing environment. ${ }^{49}$ The $\mathrm{C}$ 1s spectrum for immersed steel surface shows three peaks, as shown in Fig. 10b. The first largest peak is attributed to the $\mathrm{C}-\mathrm{C}$ and $\mathrm{C}-\mathrm{H}$ aliphatic bonds with binding energy of $284.8 \pm$ $0.02 \mathrm{eV},{ }^{50,51}$ the second is attributed to the $\mathrm{C}=\mathrm{C}$ bonds with a binding energy of $286 \pm 0.25 \mathrm{eV},{ }^{52}$ and the third peak may be assigned to the carbon atom of the $\mathrm{C}-\mathrm{O}$ and $\mathrm{C}=\mathrm{O}$ bonds in carboxylate radical with binding energy of $288.3 \pm 0.15 \mathrm{eV} .^{51,52}$ The $\mathrm{C}$ 1s spectrum consists with the carboxylate chemical structure and confirms the adsorption of inhibitors. The $\mathrm{C}=\mathrm{C}$ bonds of $\mathrm{C} 18$ shifts to negative, indicating that the $\mathrm{C}=\mathrm{C}$ bonds 


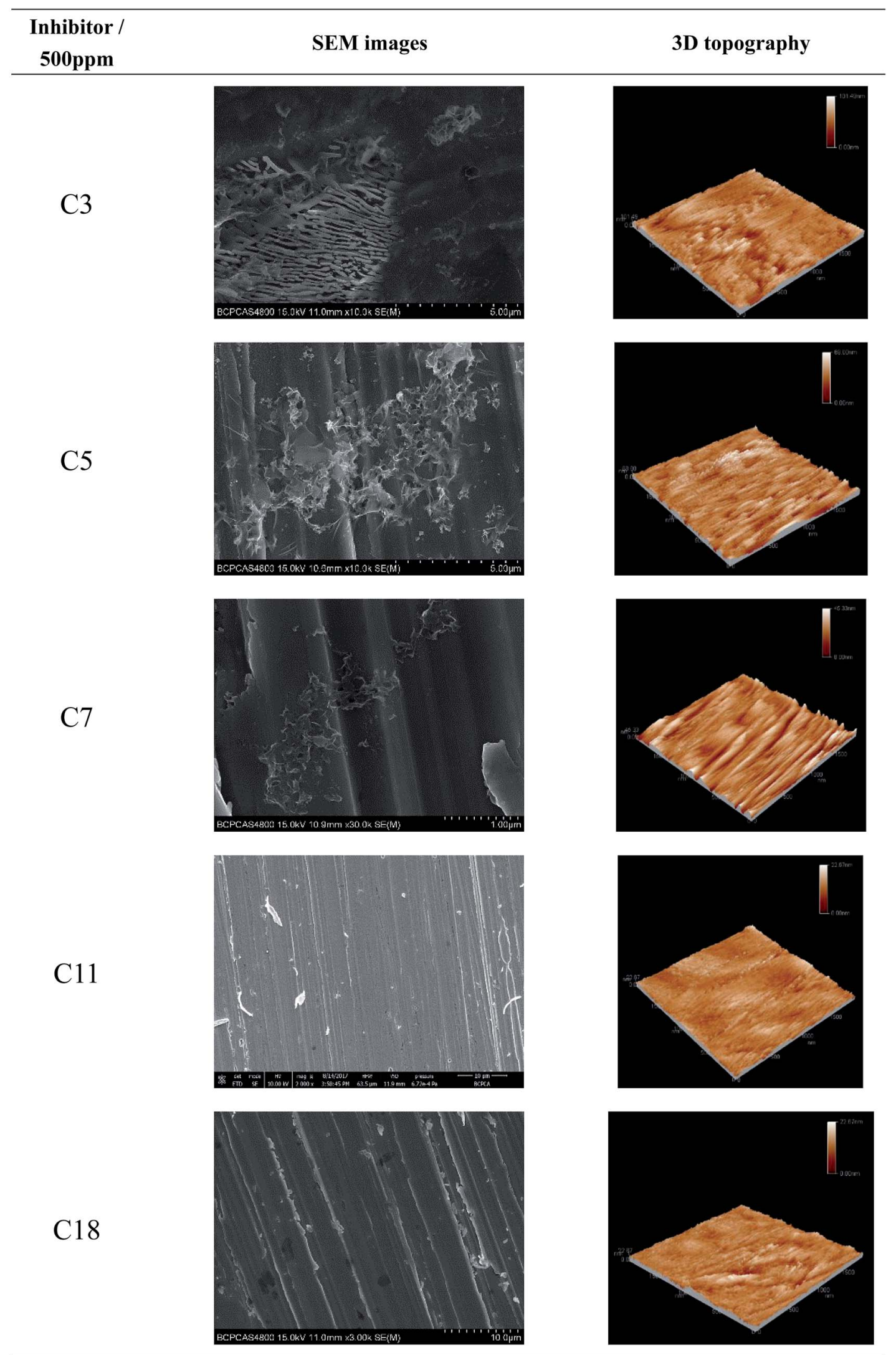

Fig. 8 SEM images and 3D topography of the steel specimens after $24 \mathrm{~h}$ exposure to the test solution with different inhibitors. 


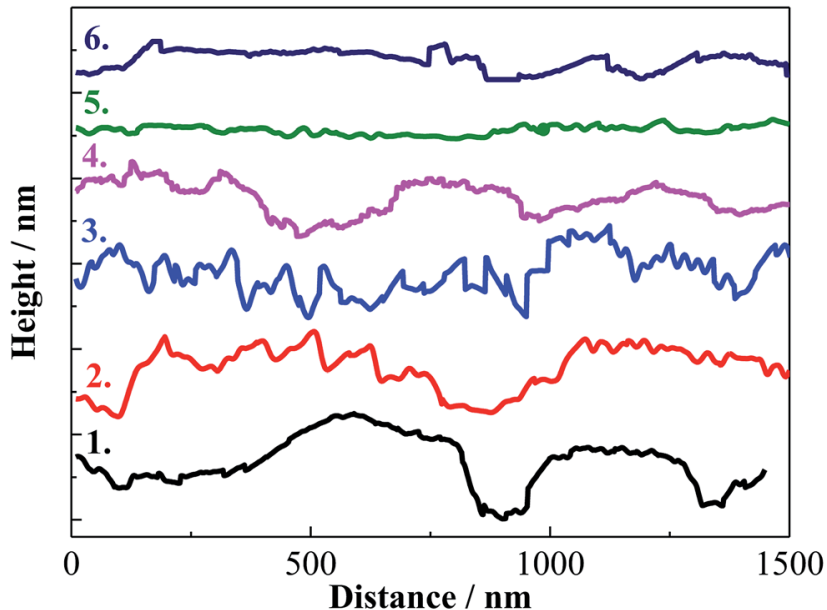

a

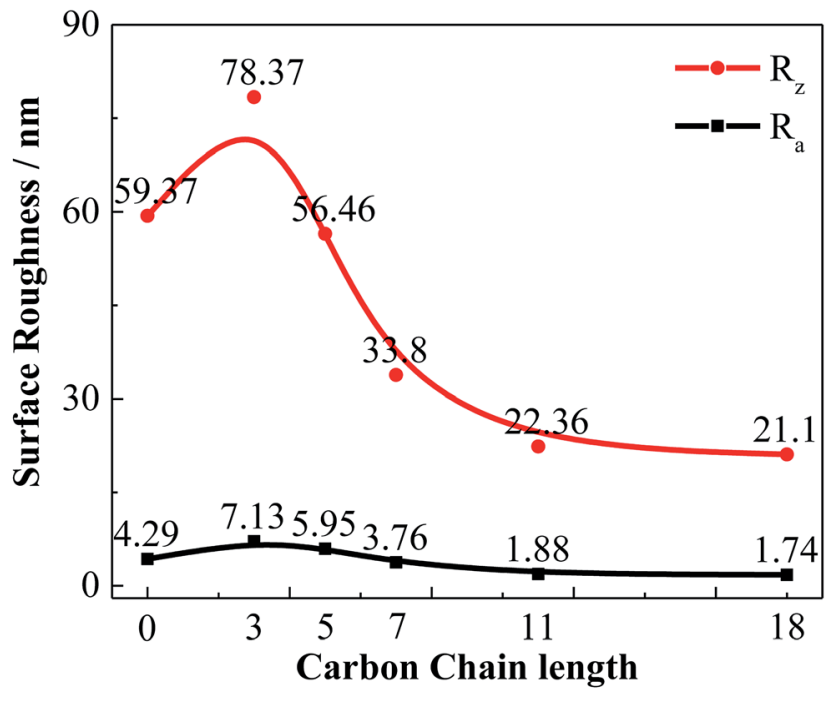

$\mathrm{b}$

Fig. 9 (a) Height profile graph of corroded steel surface in test solution for 24 hours at $298 \mathrm{~K}$, (1) without inhibitor, (2) with C3, (3) with C5, (4) with C7, (5) with C11, (6) with C18; (b) surface roughness of corroded steel surface.

accept the feedback electrons from Fe atoms ${ }^{52}$ which might lead to decrease of the inhibition effect. The $O$ is spectra for different inhibitors treated steel surface are shown in Fig. 10c. The first peak at $529.7 \pm 0.1 \mathrm{eV}$ is ascribed to $\mathrm{O}^{2-}$ which is related to the oxygen atoms bonded to Fe in $\mathrm{Fe}_{2} \mathrm{O}_{3}$ and/or $\mathrm{Fe}_{3} \mathrm{O}_{4}$ oxides. $^{51,52}$ The peaks at $531.1 \mathrm{eV}$ of $\mathrm{C}=\mathrm{O}$ and $532.3 \mathrm{eV}$ of $-\mathrm{C}-\mathrm{O}$ group show that the inhibitor adsorbed on the steel surface via the $-\mathrm{COO}^{-}$group. ${ }^{22}$ The last peak at $535.8 \mathrm{eV}$ might be attributed to oxygen in the adsorbed water. ${ }^{\mathbf{4 1}}$ These results confirm the adsorption of organic inhibitors on steel surface, and the hydrophobic film formed on steel surface could further make a contribution to reduce corrosion. The compositions of the protective films formed on carbon steel surface in the alkaline environment with studied inhibitors have no distinct difference. The carboxylate inhibitors adsorbed on the passivation

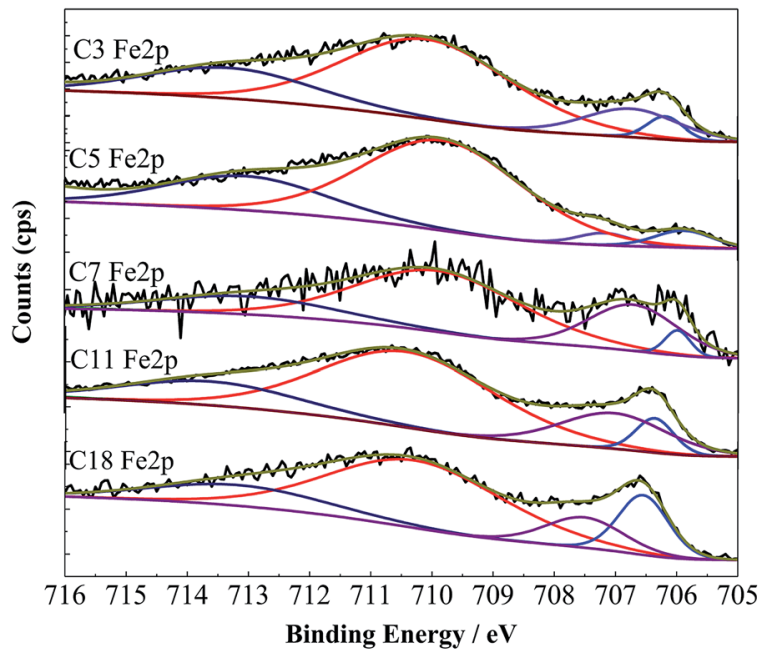

a

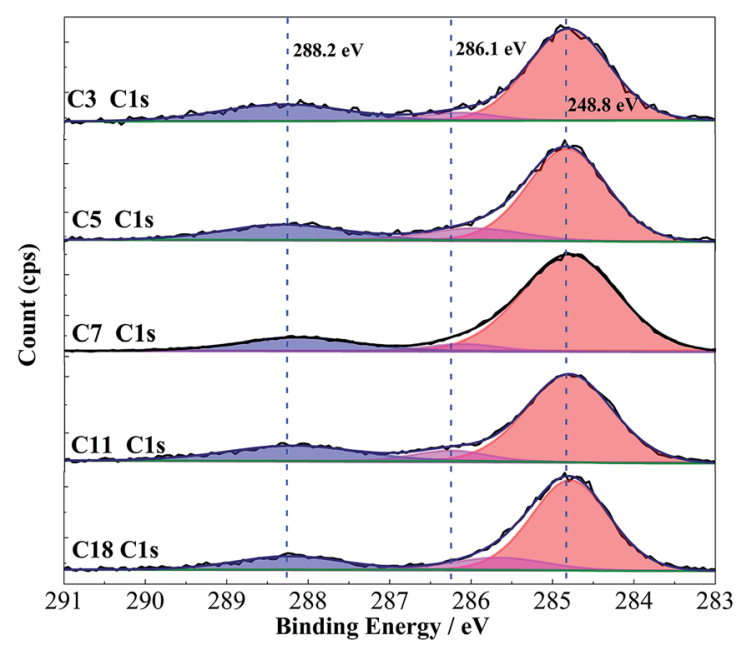

b

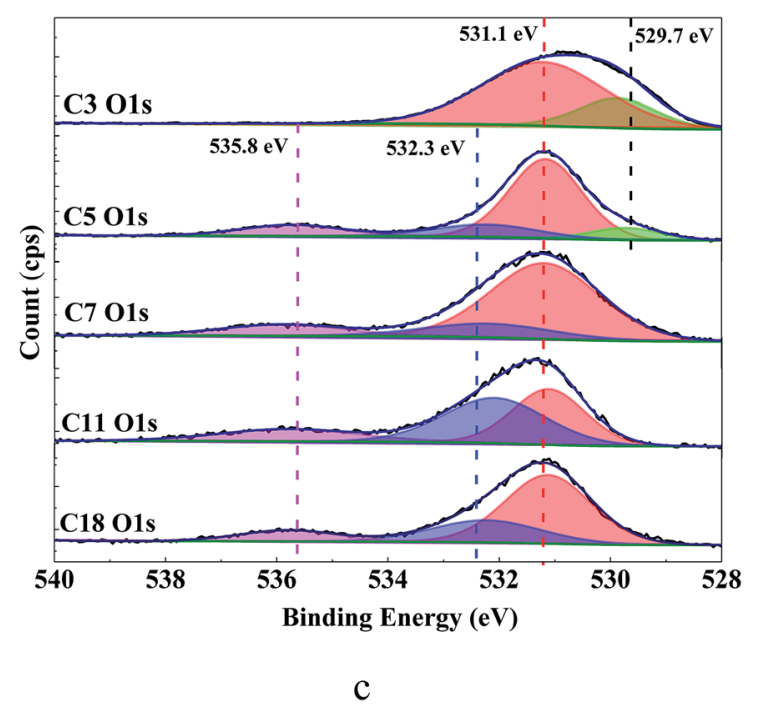

Fig. 10 XPS spectra for Q235 steel surface immersed in test solution with different inhibitors for $24 \mathrm{~h}$, (a) Fe 2p3/2, (b) C 1s, (c) $O 1 \mathrm{~s}$. 
film via the carboxylic group, and the alkylene tail would form a hydrophobic film to protect the steel from corrosion.

The surface analysis performed by Raman spectroscopy show that the corrosion inhibition of tested inhibitors is due to the formation of a chemisorption film on the steel surface. Raman spectrum of the deposited layer on the steel surface is shown in Fig. 11. The peaks at $221 \mathrm{~cm}^{-1}, 283 \mathrm{~cm}^{-1}$ and $405 \mathrm{~cm}^{-1}$ might be attributed to the iron oxide or hydroxide, such as $\mathrm{FeOOH}$ or $\mathrm{Fe}_{3} \mathrm{O}_{4}$ on the steel surface. ${ }^{53}$ The peaks at about $600-700 \mathrm{~cm}^{-1}$ might be assigned to $\mathrm{C}=\mathrm{O}$ bending absorption, ${ }^{54}$ and the peak position slightly shift to negative as the alkylene chain length increases. The peaks at about $1292 \mathrm{~cm}^{-1}$ and $1589 \mathrm{~cm}^{-1}$ are attributed to the $\mathrm{C}-\mathrm{H}$ bending and the alkylene stretching, respectively. ${ }^{37}$ The Raman results reveal the presence of a complex film formed on the steel surface which consists of iron oxide or hydroxide and carboxylate inhibitor. The formation of a complex with carboxylate inhibitor depends on the electrode potential, the solution $\mathrm{pH}$ value and inhibitor concentration. In the $\mathrm{pH} 11.5$ solution, the deprotonated inhibitor forming $\mathrm{C}_{x}-\mathrm{COO}^{-}$, and then form a complex film Fe-OOC- $\mathrm{C}_{x}$. The peaks at about $600 \mathrm{~cm}^{-1}$ shift to negative as the alkylene chain length increases, which reveals that the COO-Fe bond becomes stronger. ${ }^{55}$ The differences in solubility of different iron-carboxylate compounds lead to different inhibition effects. After the complex film formed, the alkylene chain in the inhibitor would form a hydrophobic film which could enhance the protection of the steel from the corrosion. In addition, the chloride ions may possibly take part in the complex composition as $\left[\mathrm{Fe}-\mathrm{Cl}-\mathrm{OOC}-\mathrm{C}_{x}\right]$ in the film, ${ }^{37}$ and the adsorption of chloride ions might occur by coordination of the pairs of free electrons form oxygen atoms with iron.

In short, the inhibition mechanism of carboxylate inhibitors for Q235 carbon steel in carbonated concrete pore solution is as follows: firstly, the carboxylate ions produced by the inhibitor hydrolysis may compete with $\mathrm{Cl}^{-}$during adsorption to protect

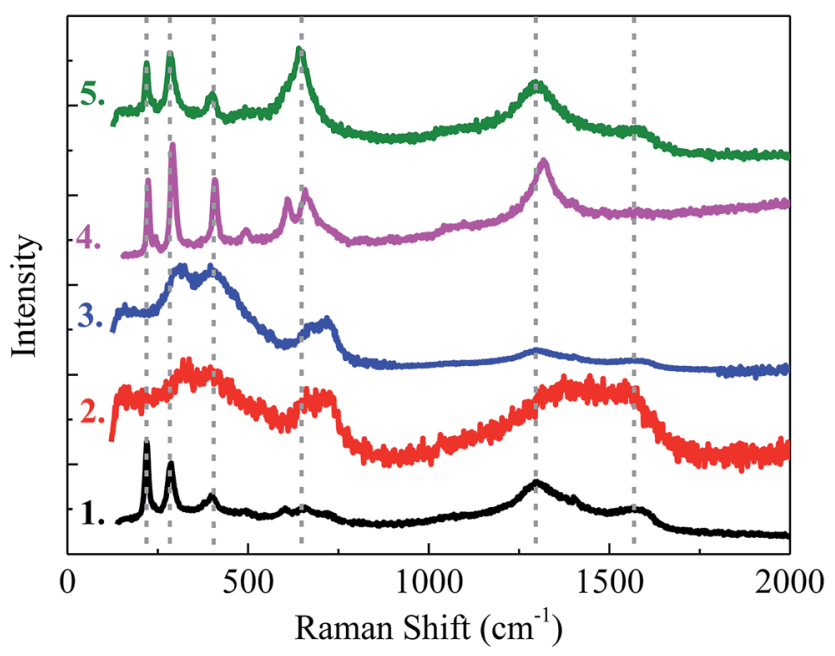

Fig. 11 Raman spectroscopy on the steel specimen after $24 \mathrm{~h}$ exposure to the test solution with different inhibitors, (1) C3, (2) C5, (3) C7, (4) $\mathrm{C} 11,(5) \mathrm{C} 18$ the matrix. In the second place, the adsorption of inhibitor via electrostatic attraction and donor-acceptor interactions could form a complex film. The $\mathrm{C}=\mathrm{C}$ bonds accept feedback electrons from Fe to enhance the adsorption. And the alkylenel tail in the carboxylate could form a hydrophobic film to enhance the protection of the steel. In addition, the inhibition effect of carboxylate inhibitors is related to the solubility of compounds, hence a longer carbon chain would have bigger hydrophobicity and a lower water solubility. At last, the carboxylate ions could get into the corrosion pits and form a deposition film to facilitate the repassivation process. As the alkylene chain length of the inhibitors increase, the inhibitor is much easier to adsorb on the steel surface, and the adsorption film shows more effective corrosion inhibition characteristic.

\section{Conclusions}

In this work, the corrosion inhibition efficiency of five kinds of carboxylate with different alkylene chain lengths on Q235 carbon steel in a simulated carbonated concrete pore solution (pH 11.5) with $0.01 \mathrm{M} \mathrm{Cl}^{-}$was studied, and the following conclusions can be drawn:

(1) The quantum chemical calculation results indicate that the HOMO is distributed over the carboxylic group, and the LUMO is distributed near the $\mathrm{C}=\mathrm{C}$ bonds. The adsorption of the studied compounds via the donate electrons from the ${ }_{-} \mathrm{COO}^{-}$, and the $\mathrm{C}=\mathrm{C}$ bonds could accept the feedback electrons from steel. The adsorption capacity of inhibitor increases with the increasing distance between the $\mathrm{C}=\mathrm{C}$ bond and the $\mathrm{COO}^{-}$.

(2) The electrochemical test results consist with the quantum chemical calculation results. The results reveal that the carboxylate inhibitors act as mix-type inhibitor. The adsorption of inhibitors lead the surface charge of steel changed to negative, and as the alkylene chain length increases, the absolute surface charge value increases.

(3) As the carbon chain length increases, the inhibition effectiveness tends to increase. The inhibitor concentration also shows important effect on the inhibition efficiency. For general corrosion, C7, C11 and C18 show inhibition effect and the IE increases with the concentration, while C3 and C5 show no inhibition. For pitting corrosion, all the tested inhibitors show inhibition effect and the IE also increases with the inhibitor concentration. Both for general corrosion and pitting, the highest IE\% is obtained in the test solution with $1000 \mathrm{ppm}$ C11.

(4) The adsorption of carboxylate compounds follows the Langmuir adsorption isotherm and the C7, C11 and C18 adsorb on steel surface via both physisorption and chemisorption. C11 and C18 can effectively reduce the surface roughness after $24 \mathrm{~h}$ expose. The surface composition results reveal that the protective films formed on carbon steel by different inhibitors have no distinct difference. The carboxylate inhibitor adsorb on steel surface by forming $\mathrm{Fe}-\mathrm{OOC}-\mathrm{C}_{x}$ compounds and the $\mathrm{C}=\mathrm{C}$ bonds could enhance the adsorption process. The alkylene tail in the inhibitors could form a hydrophobic film to protect the steel. 


\section{Conflicts of interest}

There are no conflicts to declare.

\section{Acknowledgements}

The authors would like to thank the National Natural Science Foundation of China (Contract 51210001) for support to this work.

\section{References}

1 K. Xhanari and M. Finšgar, RSC Adv., 2016, 6(67), 6283362857.

2 M. V. Diamanti, E. A. P. Rosales, G. Raffaini, F. Ganazzoli, A. Brenna, M. Pedeferri and M. Omellese, Corros. Sci., 2015, 100, 231-241.

3 Y. Cao, S. Dong, D. Zheng, J. Wang, X. Zhang, R. Du, G. Song and C. Lin, Corros. Sci., 2017, 126, 166-179.

4 F. Cao, J. Wei, J. Dong and W. Ke, Corros. Sci., 2015, 100, 365376.

5 Z. Yang, H. Fischer and R. Polder, Mater. Corros., 2013, 64(12), 1066-1074.

6 M. Jin, J. Xu, L. Jiang, Y. Xu and H. Chu, Ionics, 2015, 21(10), 2981-2992.

7 W. Mai, S. Soghrati and R. G. Buchheit, Corros. Sci., 2016, 110, 157-166.

8 G. S. Frankel, ChemInform, 1998, 29(32), 2186-2197.

9 K. K. Sankaran, R. Perez and K. V. Jata, J. Mater. Sci. Eng. A, 2001, 297(1), 223-229.

10 M. Ormellese, L. Lazzari, S. Goidanich, G. Fumagalli and A. Brenna, Corros. Sci., 2009, 51(12), 2959-2968.

11 G. T. Hefter, N. A. North and S. H. Tan, Corrosion, 1997, 53(8), 657-667.

12 G. Vastag, A. Shaban, M. Vraně̌, A. Tot, S. Belića and S. Gadžurić, J. Mol. Liq., 2018, 264(15), 526-533.

13 O. Olivares, N. V. Likhanova, B. Gómez, J. Navarrete, M. E. Llanos-Serrano, E. Arce and J. M. Hallen, Appl. Surf. Sci., 2006, 252(8), 2894-2909.

14 E. Khamis, Corrosion, 2012, 46(6), 476.

15 F. A. Azeez, O. A. Al-Rashed and A. A. Nazeer, J. Mol. Liq., 2018, 265(1), 654-663.

16 A. A. Nazeer, N. K. Allam, G. I. Youssef and E. A. Ashour, Ind. Eng. Chem. Res., 2011, 50(14), 8796-8802.

17 F. Li, S. Zhang, Y. Qiang, S. Xu, B. Tan and S. Chen, Mater. Chem. Phys., 2018, 215(15), 229-241.

$18 \mathrm{H}$. Yu, K. T. K. Chiang and L. Yang, Constr. Build. Mater., 2012, 26(1), 723-729.

19 F. E. Heakal, S. A. Rizk and A. E. Elkholy, J. Mol. Struct., 2018, 1152(15), 328-336.

20 F. E. Heakal, S. K. Attia, S. A. Rizk, M. A. Abou Essa and A. E. Elkholy, J. Mol. Struct., 2017, 1147(5), 714-724.

21 H. U. Nwankwo, L. O. Olasunkanmi and E. E. Ebenso, Sci. Rep., 2017, 7(1), 2436.

22 Z. Zhang, N. Tian, W. Zhang, X. Huang, L. Ruan and L. Wu, Corros. Sci., 2016, 111, 675-689.
23 Ş. Erdoğan, S. Z. Safi, S. Kaya, D. ÖzbakırIșın, L. Guo and C. Kaya, J. Mol. Struct., 2017, 1134(15), 751-761.

24 F. Zhang, Y. Tang, Z. Cao, W. Jing, Z. Wu and Y. Chen, Corros. Sci., 2012, 61(8), 1-9.

25 E. Honarmand, H. Mostaanzadeh, M. H. Motaghedifard, M. Hadi and M. Khayadkashani, Prot. Met. Phys. Chem. Surf., 2017, 53(3), 560-572.

26 L. H. Madkour, S. Kaya, L. Guo and C. Kaya, J. Mol. Struct., 2018, 1163, 397-417.

27 S. Rameshkumar, I. Danaee, M. Rashvandavei and M. Vijayan, J. Mol. Liq., 2015, 212, 168-186.

28 Y. wang, Y. Zuo, X. Zhao and S. Zha, Appl. Surf. Sci., 2016, 379, 98-110.

29 T. Bellezze, D. Timofeeva, G. Giuliani and G. Roventi, Cem. Concr. Res., 2018, 107, 1-10.

30 I. B. Obot and N. O. Obi-Egbedi, Corros. Sci., 2010, 52(1), 198-204.

31 G. Bereket, E. Hür and C. Öğretir, J. Mol. Struct.: THEOCHEM, 2002, 578(1), 79-88.

32 H. M. A. El-Lateef, Res. Chem. Intermed., 2016, 42(4), 32193240.

33 A. Popova, E. Sokolova, S. Raicheva and M. Christov, Corros. Sci., 2003, 45(1), 33-58.

34 R. Solmaz, G. Kardaș, M. Çulha, B. Yazici and M. Erbil, Electrochim. Acta, 2008, 53(20), 5941-5952.

35 M. A. Amin, S. S. A. El-Rehim, E. E. F. El-Sherbini and R. S. Bayoumi, Electrochim. Acta, 2007, 52(11), 3588-3600.

36 N. Dinodi and A. N. Shetty, Corros. Sci., 2014, 85(4), 411-427.

37 M. M. Mennucci, E. P. Banczek, R. P. R. Rodrigues and I. Costa, Cem. Concr. Compos., 2009, 31(6), 418-424.

38 A. S. Fazayel, M. Khorasani and A. A. Sarabi, Appl. Surf. Sci., 2018, 441, 895-913.

39 ASTM G61-86, ASTM International, United States, 2009, pp. 19428-22959.

40 F. Blin, P. Koutsouko, P. Klepetsianis and M. Forsyth, Electrochim. Acta, 2007, 52(21), 6212-6220.

41 M. Bouanis, M. Tourabi, A. Nyassi, A. Zarrouk, C. Jama and F. Bentiss, Appl. Surf. Sci., 2016, 389(15), 952-966.

42 M. Lagrenée, B. Mernari, N. Chaibi, M. Traisnel, H. Vezin and F. Bentiss, Corros. Sci., 2001, 43(5), 951-962.

43 A. M. Al-Sabagh, H. M. Abd-El-Bary, R. A. El-Ghazawy, M. R. Mishrif and B. M. Hussein, Egypt. J. Pet., 2011, 20(2), 33-45.

44 S. A. Ali, M. T. Saeed and S. U. Rahman, Corros. Sci., 2003, 45(2), 253-266.

45 M. A. Quraishi and R. Sardar, Mater. Chem. Phys., 2003, 78(2), 425-431.

46 B. Tan, S. Zhang, Y. Qiang, L. Guo, L. Feng, C. Liao, Y. Xu and S. Chen, J. Colloid Interface Sci., 2018, 526(15), 268-280.

47 R. Dudric, A. Vladescu, V. Rednic, M. Neumann, I. G. Deac and R. Tetean, J. Mol. Struct., 2014, 1073(5), 66-70.

48 N. Nakayama and A. Obuchi, Corros. Sci., 2003, 45(9), 20752092.

49 A. Galtayries, R. Warocquier-Clérout, M. D. Nagel and P. Marcus, Surf. Interface Anal., 2006, 38(4), 186-190.

50 S. P. Trasatti, Corros. Rev., 2015, 33(6), 373-393. 
51 I. Frateur, A. Carnot, S. Zanna and P. Marcus, Appl. Surf. Sci., 2006, 252(8), 2757-2769.

52 X. Pang, X. Ran, F. Kuang, J. Xie and B. hou, Chin. J. Chem. Eng., 2010, 18(2), 337-345.

53 N. Gartner, T. Kosec and A. Lega, Mater. Chem. Phys., 2016, 184, 31-40.
54 J. A. Calderón, F. A. Vásquez and J. A. Carreño, Mater. Chem. Phys., 2017, 185, 218-226.

55 S. T. Selvi, V. Raman and N. Rajendran, J. Appl. Electrochem., 2003, 33(12), 1175-1182. 